\title{
An Aggressive Ameloblastic Fibroma in Maxilla of a 5-Year-Old Child- Reconstruction of the Defect with Buccal Flap Advancement-A Conservative Approach
}

\author{
Dayashankara Rao JK, Aadya Sharma*, Shalender Sharma, Varun Arya, Ripan Das \\ Department of Maxillofacial Surgery, Faculty of Dental Sciences, SGT University, Gurgaon, India \\ Email: "dr.aadyasharma@gmail.com
}

Received 17 April 2015; accepted 17 August 2015; published 20 August 2015

Copyright (C) 2015 by authors and Scientific Research Publishing Inc.

This work is licensed under the Creative Commons Attribution International License (CC BY).

http://creativecommons.org/licenses/by/4.0/

(c) (i) Open Access

\begin{abstract}
Ameloblastic fibroma (AF) is a rare tumour of mixed odontogenic origin that can occur either in mandible or maxilla but is most frequently found in the posterior region of mandible. Age of occurrence is generally between first and second decades of life. It is often mistaken for a dentigerous cyst due to presence of an impacted tooth. The diagnosis of AF usually occurs accidentally by routine radiographic examination for an impacted tooth. Histologically it consists of odontogenic ectomesenchyme resembling the dental papilla, epithelium resembling dental lamina and enamel organ without dental hard tissues. There is controversy in the literature as to whether the treatment should be conservative or a radical resection should be done. A conservative treatment strategy, such as enucleation and curettage, is usually sufficient. We describe a case of massive ameloblastic fibroma in a 5-year-old child with an unusual position in maxillary posterior region and without any impacted tooth. Surgical resection of the tumor through Weber Ferguson approach was done under GA with 2 years of follow-up without any recurrence.
\end{abstract}

\section{Keywords}

Ameloblastic Fibroma, Odontogenic Tumours, Ectomesenchyme, Maxilla

\footnotetext{
${ }^{*}$ Corresponding author.
}

How to cite this paper: JK, D.R., Sharma, A., Sharma, S., Arya, V. and Das, R. (2015) An Aggressive Ameloblastic Fibroma in Maxilla of a 5-Year-Old Child-Reconstruction of the Defect with Buccal Flap Advancement-A Conservative Approach. International Journal of Clinical Medicine, 6, 579-585. http://dx.doi.org/10.4236/ijcm.2015.68077 


\section{Introduction}

$\mathrm{AF}$ is a rare tumour of mixed odontogenic origin. It generally occurs in young age due to which it has a very high diagnostic consideration [1]. The most common site of occurrence is mandibular posterior region although it can also arise from maxilla [2]. AF and related lesions are defined by WHO as neoplasms composed of proliferating odontogenic epithelium embedded in a cellular ectomesenchymal tissue that resembles dental papilla, with varying degrees of inductive change and dental hard tissue formation [3]. Although more than 150 cases have been published, conflicting data exist in the literature on the clinical characteristics [4]. Edema and/or an increase in volume are the main signs of AF, although most cases are asymptomatic. Some are found incidentally by microscopic examination of the dental follicular tissue of unerupted teeth while others appear as large expanding lesion suggestive of neoplasm [5]. Primary lesions can usually be treated conservatively, with enucleation or curettage, and the tumour has a low rate of recurrence [6]. We describe a case of massive ameloblastic fibroma in a 5-year-old patient in the maxillary posterior region, a rare site for its occurrence with no impacted tooth associated with the lesion.

\section{Case Report}

A 5-year-old boy reported to the Department of Oral \& Maxillofacial Surgery, Faculty of Dental Sciences, SGT University, Gurgaon with the chief complaint of a huge painless swelling on left side of the face since 2 years. The swelling was insidious in onset and gradually increased to the present size. He reported having no pre-existing medical conditions, fever or other signs of infection.

On extra-oral examination, there was facial asymmetry with an increase in volume on the left side of the face. The swelling extended supero-inferiorly about $1 \mathrm{~cm}$ below the left infraorbital margin to the lower border of mandible (Figure 1 and Figure 2). There was obliteration of the nasolabial fold. Left ala of the nose and the left corner of the mouth were stretched and pushed downwards. The swelling extended medio-laterally from the obliterated nasolabial fold and facial midline to a line drawn vertically downwards from the lateral orbital fissure to the mandible on the left side. Intraorally, the lesion was whitish, non tender, smooth with a rubbery texture and poorly defined margins. It measured approximately $8 \times 5 \mathrm{~cm}$ in size. The swelling was associated with a

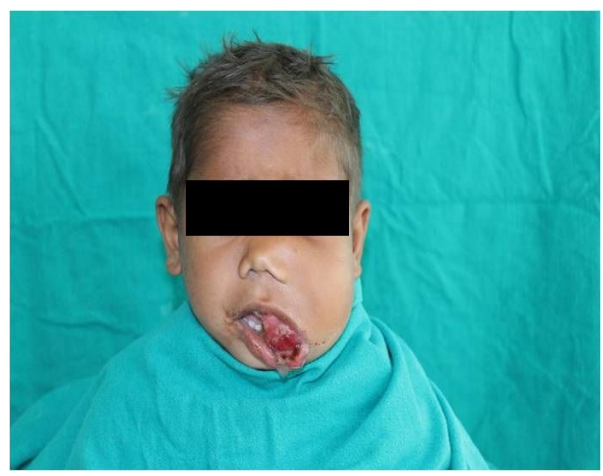

Figure 1. Preoperative photograph (extra oral) showing the aggressive lesion.

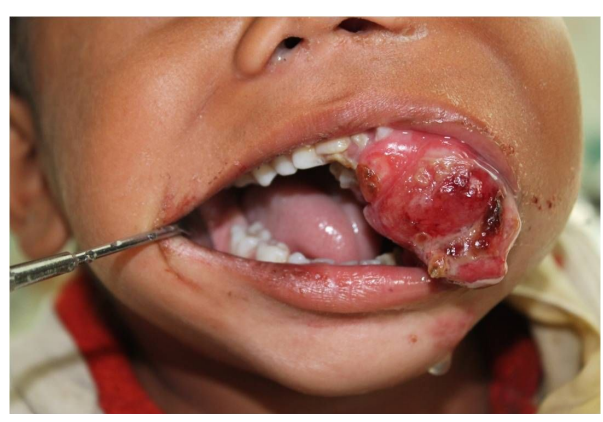

Figure 2. Preoperative photograph (intra oral). 
compromised vestibular fornix in the left side maxilla and severely displaced teeth 64 and 65 . The swelling was accompanied by difficulty in swallowing and speech. Radiographic examination revealed a unilocular lesion, displacement of 64 and 65 and cortical bone expansion in antero-posterior and supero-inferior direction (Figure 3). Tomographic examination through $3 \mathrm{D}$ reconstruction indicated vestibular fenestration of the cortical bone till the infra orbital margin and anteriorly till the lateral wall of the nose (Figure 4). Aspiration was negative and an incisional biopsy was performed.

The microscopic examination revealed proliferation of odontogenic epithelial tissue and highly cellular mesenchymal tissue. Routine stains like hematoxylin and eosin were used. Microscopically, the tumour was composed of cell-rich mesenchymal tissue resembling the primitive dental papilla admixed with proliferating odontogenic epithelium (Figure 5 and Figure 6). Based on the clinical, imaging and microscopic data, a diagnosis of ameloblastic fibroma was established. Enucleation of the lesion was done by using Weber Ferguson incision

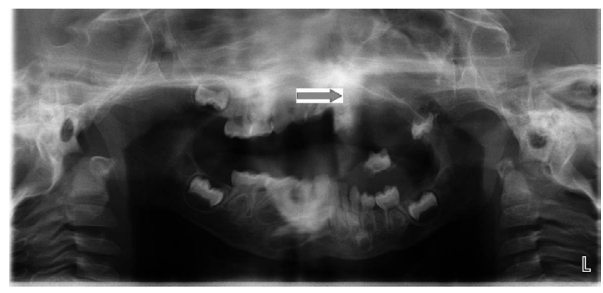

Figure 3. Orthopantomograph (OPG) radiograph.

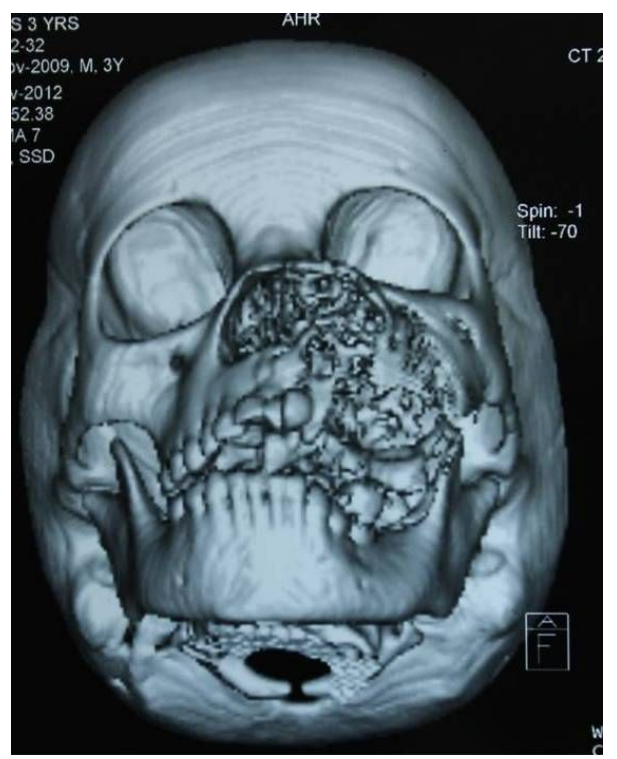

Figure 4. Preoperative 3D CT.

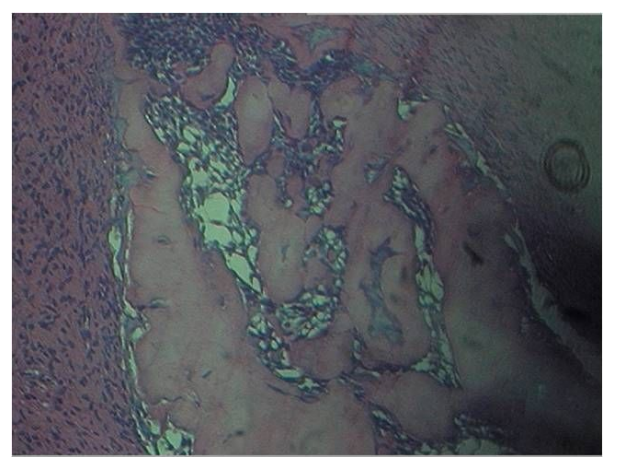

Figure 5. Histopathological photomicrograph. 


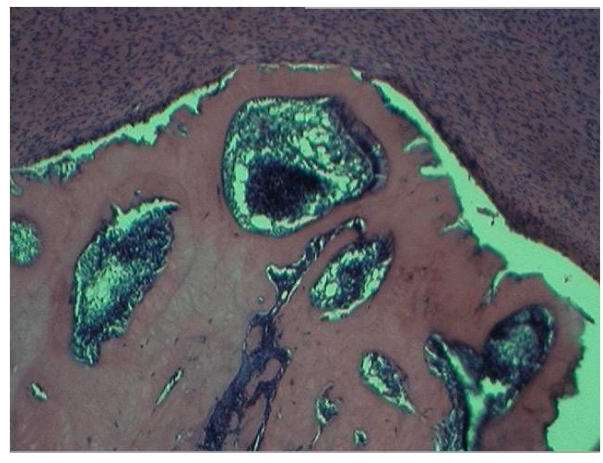

Figure 6. Histopathological photomicrograph.

under general anaesthesia (Figure 7 and Figure 8). A conservative approach was used for reconstruction using buccal flap advancement. The patient is on regular follow-up for 2 years. The outcome has been functionally and aesthetically satisfactory and there have been no signs of recurrence (Figures 9-11). The patient's parents gave their consent for the case report to be published.

\section{Discussion}

Treatment of ameloblastic fibroma is controversial. Conservative treatment like enucleation and curettage is usually sufficient. However, radical treatment is required for aggressive lesions. The obvious advantage of conservative treatment over radical treatment is minimal anatomical distortion of the involved region.

AF generally occurs between 1 st and 2nd decade of life in contrast to the present case which occurred at an early age of 1.5 years. AF is generally associated with impacted tooth in the posterior region of mandible, angle and/or ramus [7]. Our case is unique because the lesion is present in the maxillary posterior region which is a rare site for its occurrence.

The radiographic appearance may vary from a small unilocular lesion to an extensive multilocular lesion [7]. Bone expansion, tooth impaction and dislocation are common findings. In the presented case, radiographic examination revealed a large unilocular lesion with tooth displacement but no impacted tooth; this was an unusual finding for this kind of lesion. The tomography images of the reported case revealed fenestration of the cortical bone, a characteristic of extensive and long-standing lesions but rarely observed in AF.

Histologically, AF is a true mixed tumor, as it has both mesenchymal and epithelial neoplastic components with no associated calcified tissue [2]. Ameloblastic fibro-odontoma (AFO) is defined as a tumor that shares many features with AF but has enamel and dentin in its interior [8]. Some authors consider this lesion as an intermediate stage in the development of an odontoma, with the primary stage of formation being AF [9]. As some odontomas have similar histological features to AF and AFO, clinical findings are fundamental for the differentiation of these three pathological entities. If all cases occurred following the particular developmental stage outlined above, AF would affect young patients, odontoma would occur in elderly patients, and AFO would be seen in an intermediate age group. However, this is not the case. But in our case this statement holds true as our patient's age is 5 years and he is giving a history of 3.5 years. In the past, AF was regarded as a variant of ameloblastoma, but it has recently been considered to be of odontogenic epithelial origin.

An aggressive surgical treatment is suggested by some authors because of the possibility of malignant transformation of an AF to an ameloblastic fibrosarcoma [10] [11]. Muller et al. [10] reported that since 1960, 44\% cases of ameloblastic fibrosarcoma (19/43) had arisen from AF. There is also the consideration that the majority, if not all, of AFs are true neoplasms with a potential to recur and/or of malignant transformation and that some, especially those occurring during childhood, can represent the primitive stage of a developing odontoma [10]. On reviewing the literature with 85 cases of AF, the recurrence rate of AF found by Trodahl et al. [5] was 43.5\%; while that found by Zallen et al. [12] was 18.3\%. Lysell and Sund [13] proposed the incomplete primary removal as a reason of recurrence in their cases. This was supported by Mosby et al. [14] explaining that after the complete removal of a tumour clinically, this could not be stated at a cellular level. They suggested conservative removal of $\mathrm{AF}$ and modified block resection of any recurrence.

The prognosis for lesions of this proportion is dubious. In young patients with small lesions that respond well to conservative treatment, we recommend enucleation and curettage. However, in extensive lesions with the in- 


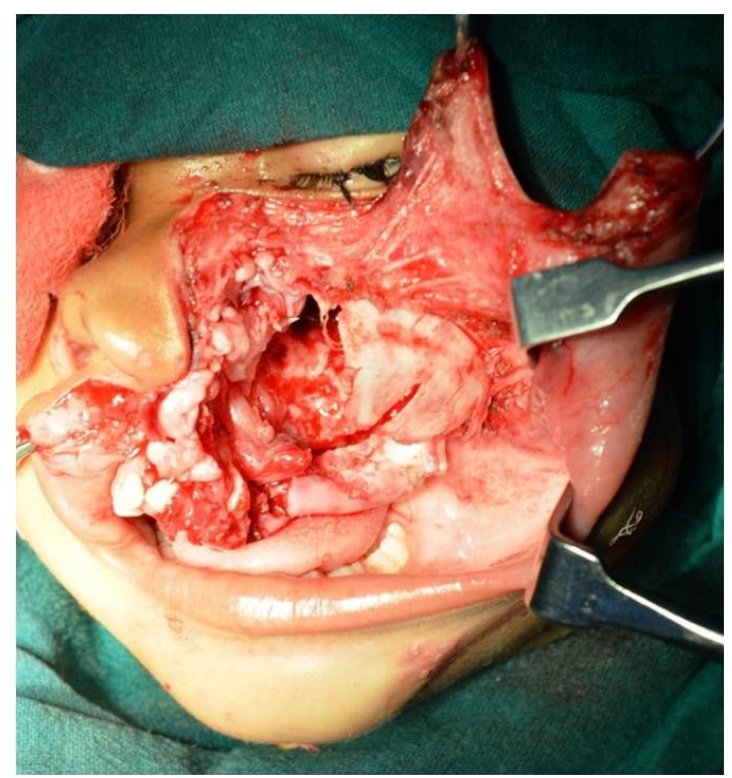

Figure 7. Intraoperative photograph.

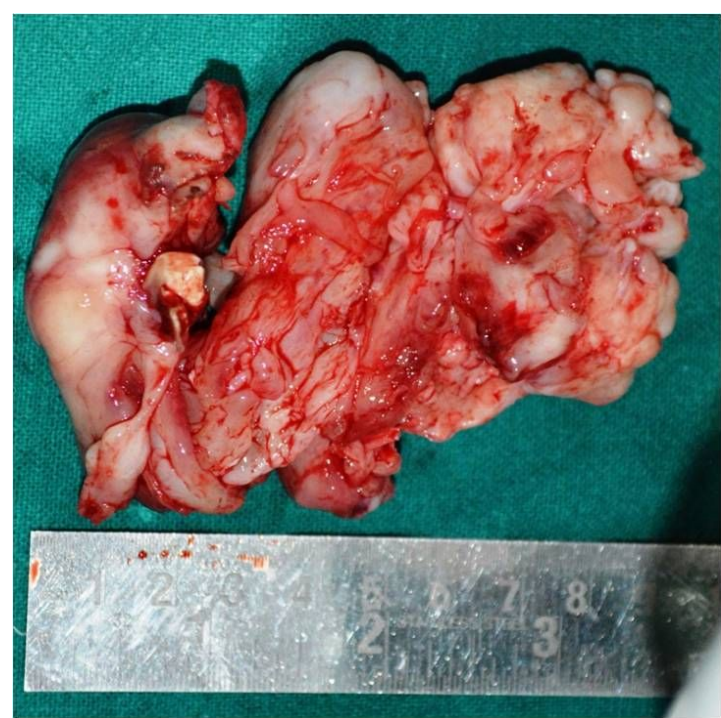

Figure 8. Resected specimen.

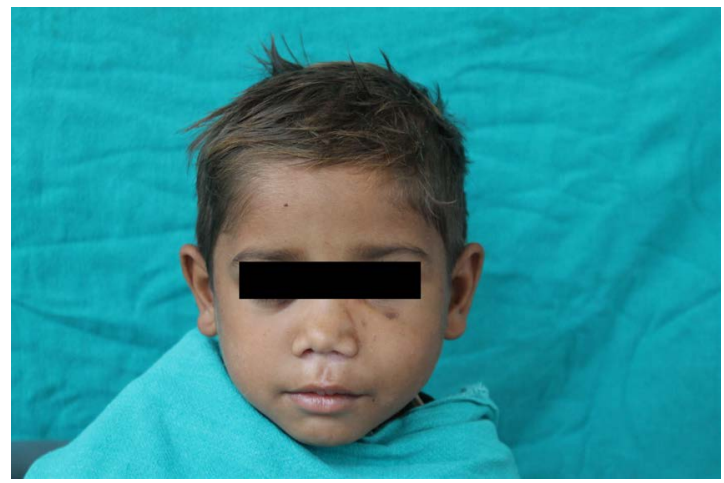

Figure 9. Postoperative photograph (extra oral). 


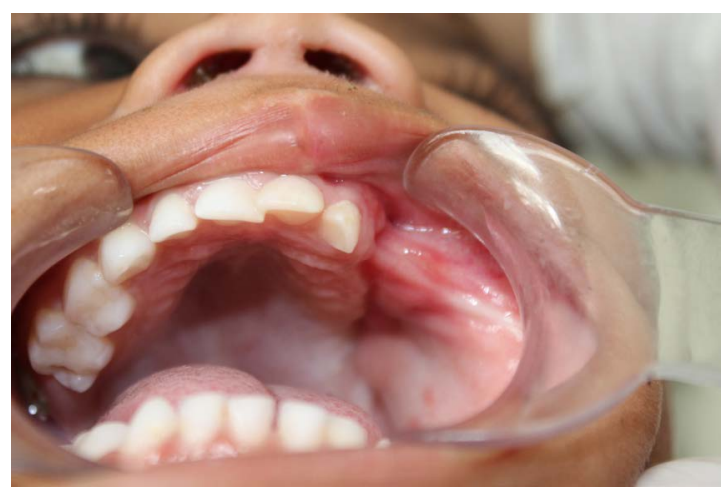

Figure 10. Postoperative photograph (intra oral).

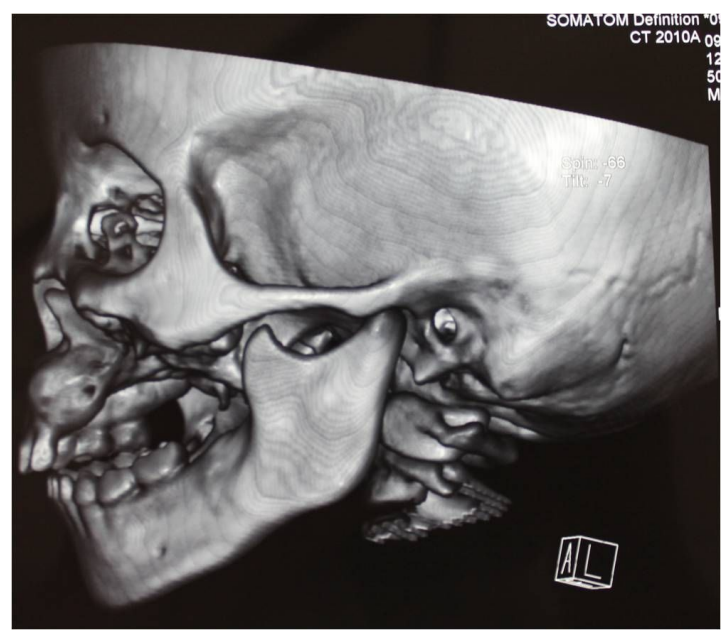

Figure 11. Postoperative 3D CT.

volvement of adjacent tissues, we recommend block resection.

In this particular case, even though the lesion was extensive, it was treated conservatively. The child is disease free and is leading a normal healthy life post surgery.

Regardless of the form of treatment, patients with $\mathrm{AF}$ must be followed up for a long period to enable the early detection of possible recurrence or development of ameloblastic fibrosarcoma, which is the malignant counterpart of AF [15] [16]. In the case described here, the patient has been followed up for two years with no signs of recurrence or sarcomatous transformation, thereby demonstrating the success of the treatment. Hence, we would like to conclude that each case needs to be treated judiciously in terms of the surgical approach.

\section{Source(s) of Support}

None identified.

\section{Presentation at a Meeting}

Nil.

\section{Conflicting Interest}

None identified.

\section{References}

[1] Jones, A.V. and Franklin, C.D. (2006) An Analysis of Oral Andmaxillofacial Pathology Found in Children over a 
30-Year Period. International Journal of Paediatric Dentistry, 16, 19-30. http://dx.doi.org/10.1111/j.1365-263X.2006.00683.x

[2] Costa, D.O., Alves, A.T., Calasans-Maia, M.D., Cruz, R.L. and Lourenço Sde, Q. (2011) Maxillary Ameloblastic Fibroma: A Case Report. Brazilian Dental Journal, 22, 171-174. http://dx.doi.org/10.1590/S0103-64402011000200015

[3] Kramer, I.R.H., Pindborg, J.J. and Shear, M. (1992) Histological Typing of Odontogenic Tumors. 2nd Edition, WHO International Histological Classification of Tumors, Springer Verlag, Berlin, 16-18. http://dx.doi.org/10.1007/978-3-662-02858-2

[4] Philipsen, H.P., Reichart, P.A. and Praetorius, F. (1997) Mixed Odontogenic Tumours and Odontomas. Considerations on Interrelationship. Review of the Literature and Presentation of 134 New Cases of Odontomas. Oral Oncology, 33, 86-99. http://dx.doi.org/10.1016/S0964-1955(96)00067-X

[5] Trodahl, J.N. (1972) Ameloblastic Fibroma. A Survey of Cases from the Armed Forces Institute of Pathology. Oral Surgery, Oral Medicine, Oral Pathology, 33, 547-558. http://dx.doi.org/10.1016/0030-4220(72)90367-2

[6] Chindia, M.L., Akama, M.K. and Awange, D.O. (2005) Ameloblastic Fibroma at the University of Nairobi Dental Hospital. East African Medical Journal, 82, 418-421.

[7] Rao, S.P., Srivastava, G. and Smitha, B. (2012) Ameloblastic Fibroma. Journal of Oral and Maxillofacial Pathology, 16, 444-445. http://dx.doi.org/10.4103/0973-029X.102515

[8] Martín-Granizo López, R., Ortega, L., González Corchón, M.A. and Berguer Sández, A. (2003) Ameloblastic Fibroma of the Mandible. Report of Two Cases. Med Oral., 8, 150-153.

[9] Chen, Y., Wang, J.M. and Li, T.J. (2007) Ameloblastic Fibroma: A Review of Published Studies with Special Reference to Its Nature and Biological Behavior. Oral Oncology, 43, 960-969. http://dx.doi.org/10.1016/j.oraloncology.2007.05.009

[10] Muller, S., Parker, D.C., Kapadia, S.B., Budnick, S.D. and Barnes, E.L. (1995) Ameloblastic Fibrosarcoma of the Jaws. A Clinicopathologic and DNA Analysis of Five Cases and Review of the Literature with Discussion of Its Relationship to Ameloblastic Fibroma. Oral Surgery, Oral Medicine, Oral Pathology, Oral Radiology, and Endodontology, 79, 469477. http://dx.doi.org/10.1016/S1079-2104(05)80130-1

[11] Takeda, Y., Kaneko, R. and Suzuki, A. (1984) Ameloblastic Fibrosarcoma in the Maxilla, Malignant Transformation of Ameloblastic Fibroma. Virchows Archiv A Pathological Anatomy and Histopathology, 404, 253-263. http://dx.doi.org/10.1007/BF00694891

[12] Zallen, R.D., Preskar, M.H. and McClary, S.A. (1982) Ameloblastic Fibroma. Journal of Oral and Maxillofacial Surgery, 40, 513-517. http://dx.doi.org/10.1016/0278-2391(82)90014-3

[13] Lysell, L. and Sund, G. (1978) Ameloblastic Fibroma: Report of Two Cases. British Journal of Oral Surgery, 16, 7885. http://dx.doi.org/10.1016/S0007-117X(78)80060-2

[14] Mosby, E.L., Russell, D., Noren, S. and Barker, B.F. (1998) Ameloblastic Fibroma in a 7-Week-Old Infant: A Case Report and Review of the Literature. Journal of Oral and Maxillofacial Surgery, 56, 368-372.

[15] Reichart, P.A. and Jundt, G. (2008) Benigne "gemischte" odontogene Tumoren. Der Pathologe, 29, 189-198. (In German) http://dx.doi.org/10.1007/s00292-008-0996-0

[16] Sultan, A., Rao, J.D. and Jain, H. (2013) An Aggressive Ameloblastic Fibroma in a 9-Year-Old Child Treated with Buccal Fat Graft. Journal of Cranio-Maxillary Diseases, 2, 80-84. http://dx.doi.org/10.4103/2278-9588.113583 